\title{
Treatment of Mild-to-Moderate Plaque Psoriasis with a New 650-Microsecond 1064-nm Nd:YAG Laser: Clinical and Dermoscopic Assessment
}

\author{
Marta Kołt-Kamińska · Magdalena Żychowska · Adam Reich (D)
}

Received: December 7, 2020 / Accepted: January 9, 2021 / Published online: January 19, 2021

(c) The Author(s) 2021

\begin{abstract}
Introduction: About $70-80 \%$ of patients with psoriasis suffer from mild disease, and new modalities of topical treatment are urgently needed. This study aims to evaluate the effectiveness of 650-microsecond 1064-nm Nd:YAG laser in the therapy of psoriatic plaques and assess the utility of dermoscopy in predicting treatment response.
\end{abstract}

Methods: Ten patients (mean age $37.4 \pm 16.2$ years) with stable plaque-type psoriasis were enrolled. The microsecond Nd:YAG laser treatment was applied to representative plaques on day $0,7,14$, and 21 . Clinical and dermoscopic photographs were performed at each session and follow-up visit (day 28). The disease severity was assessed using modified Psoriasis Area and Severity Index (mPASI) and Investigator Global Assessment (IGA). Patients were asked to rate the intensity of subjective symptoms, tolerability, and final outcome of the treatment.

Results: Significant improvement of all mPASI components was observed, although the maximal mean reduction of total mPASI was only $30.3 \%$. At baseline, three patients were assessed

M. Kołt-Kamińska · M. Żychowska · A. Reich ( $\square)$ Department of Dermatology, Institute of Medical Sciences, Medical College of Rzeszow University, Rzeszow, Poland

e-mail: adi_medicalis@go2.pl as "moderate" and seven as "mild" according to IGA, while on day 28, eight patients were scored as "mild" and two as "almost clear." Complete resolution of itching was achieved in all patients. Local adverse reactions were also observed, which resulted in moderate tolerance of treatment in four patients. Three participants reported marked improvement on day 28, although $30 \%$ of patients observed no benefit. All subjects with dotted vessels, linear vessels, or hemorrhagic spots under dermoscopy at baseline reported some improvement after laser therapy. Three out of six patients with globular vessels were unresponsive to Nd:YAG laser.

Conclusions: Microsecond Nd:YAG laser treatment may provide some improvement of psoriatic plaques, but its routine applicability seems to be limited due to ambiguous efficacy and local adverse reactions. Dermoscopy may be useful in identifying patients who will benefit from the procedure.

Keywords: Dermoscopy; Laser; Nd:YAG laser; Psoriasis; Topical therapy; Treatment 


\section{Key Summary Points}

\section{Why carry out this study?}

There is a need for novel local treatment modalities for patients with mild psoriasis.

The aim of the current research was to evaluate the efficacy and tolerability of 650-microsecond Nd:YAG laser in the therapy of mild-to-moderate plaque psoriasis and to assess the utility of dermoscopy in predicting treatment response.

\section{What was learned from the study?}

650-Microsecond Nd:YAG laser may lead to some improvement of the psoriatic plaques, but the results are not satisfactory enough to recommend this procedure as a routine first- or second-line treatment option for plaque psoriasis.

Dermoscopy may be of help in initial identification of psoriatic plaques that may respond to microsecond Nd-YAG laser treatment.

\section{DIGITAL FEATURES}

This article is published with digital features, including a summary slide, to facilitate understanding of the article. To view digital features for this article go to https://doi.org/10.6084/ m9.figshare.13547552.

\section{INTRODUCTION}

Psoriasis is a chronic inflammatory skin disease affecting about $1-3 \%$ of the general population. The pathogenesis of psoriasis is still not fully elucidated, but it is generally accepted that immunological, genetic, and some environmental factors play major roles [1, 2]. Better understanding of psoriasis pathogenesis resulted in an enormous progress in the

development of new systemic, highly effective antipsoriatic therapies. However, about $70-80 \%$ of patients with psoriasis suffer from mild disease and usually require only local treatment $[1,3]$. Despite this fact, progress in the development of novel topical therapies is much less apparent. It is worth emphasizing that personalization of topical treatment is also necessary. Among the factors that motivate us to search for new modalities of local treatment is the inconvenience of daily use of anthralin ointment, as well as the growing tendency to demonstrate steroid phobia in some patients, and the addiction and overuse of topical corticosteroids in others. Recently, we tested topical cefazolin as a potential antipsoriatic alternative to topical corticosteroids [4]. Here, we want to present data on the use of a novel 650-microsecond $1064 \mathrm{Nd}$ :YAG laser in the treatment of psoriatic plaques.

Light treatment, including but not limited to broadband ultraviolet (UV) B, narrow-band monochromatic UVB (311-313 nm), laser UVB, PUVA (psoralens and UVA), UVA1, visible light, monochromatic light within the visible spectrum, and infrared light, has been used in the treatment of skin diseases for decades. Light may exert immunosuppressive and antiinflammatory effects. Moreover, UVB radiation demonstrates antiproliferative effects by affecting nuclear DNA [5]. It is worth emphasizing that therapy with light-emitting diodes (LEDs) is also gaining popularity, as research results are promising and the effectiveness of this therapy seems to be comparable to other methods of phototherapy [6]. In addition, increasing use of lasers in the treatment of inflammatory skin conditions is being observed. There are several reports demonstrating high effectiveness of the excimer laser in the treatment of plaque psoriasis [7-9], while the long-pulsed $1064 \mathrm{Nd}$ :YAG laser has already been shown to be effective in the treatment of nail psoriasis [10-12]. The Nd:YAG laser may potentially be a good alternative to topical therapies due to its selective action on target areas or an additional option for patients with resistant psoriatic plaques.

The aim of the current study is to evaluate the effectiveness and tolerability of the novel 650-microsecond 1064-nm Nd:YAG laser in the 
treatment of psoriatic plaques and to assess the utility of dermoscopy in predicting treatment response.

\section{METHODS}

\section{Patients}

Patients with stable mild-to-moderate plaquetype psoriasis of at least 6-month duration, who were candidates for topical therapy and were able and willing to come once a week for four weeks for laser treatment, were enrolled for the study in September 2020. Patients undergoing antipsoriatic treatment and those who had been treated for psoriasis with topical/systemic agents or phototherapy in the prior 12 weeks were not considered eligible. The exclusion criteria were as follows: history of photosensitivity, pregnancy, lactation, systemic therapy with retinoids or photosensitizing drugs or herbs which cannot be stopped, topical therapy with photosensitizing substances, epilepsy, tendency to scarring, and excessive suntan. In total, ten patients (nine male and one female) with mean age of $37.4 \pm 16.17$ years (range $12-69$ years) with stable plaque-type psoriasis were enrolled in this study. All participants were Caucasians with Fitzpatrick skin types I-II. The mean duration of psoriasis was $9.7 \pm 9.65$ years (range 1-27 years); $20 \%$ of included patients had family history of psoriasis. Detailed characteristics of the study participants are presented in Table 1.

The research was conducted in accordance with the Declaration of Helsinki and was approved by the Ethics Committee at the University of Rzeszow. All subjects or their legal representatives signed an informed consent form before initiation of the study.

\section{Study Design}

After providing written informed consent, a representative area was chosen on each patient (one large psoriatic plaque or a few smaller ones with total area of about $4-6 \mathrm{~cm}^{2}$ ). The target plaques were located predominantly on the lower limbs $(n=6)$, followed by upper limbs $(n=3)$ and trunk $(n=1)$. The 650-microsecond 1064-nm Nd:YAG laser treatment was applied to the selected area on day $0,7,14$, and 21 . The laser settings were predetermined and were the same for all patients (energy $255 \mathrm{~J} / \mathrm{cm}^{2}$, pulse width $650 \mu \mathrm{s}$, spot diameter $2 \mathrm{~mm}$ ). During the 4-week study period, patients were asked not to apply any active antipsoriatic substances to the laser-treated area. The use of emollients was allowed. The follow-up visit was scheduled for day 28. At each study visit (day $0,7,14,21$, and 28 ), clinical and dermoscopic assessments with photographic documentations of the psoriatic plaques were performed. Two dermatologists (M.K.-K. and M.Ż.) performed the evaluations, and all discrepancies were discussed until consensus was reached. Disease severity was assessed at each study visit according to the modified Psoriasis Area and Severity Index (mPASI), which is the sum of the intensity of erythema, induration, and desquamation, and the Investigator Global Assessment (IGA) with following descriptors: clear (IGA 0), almost clear (IGA 1), mild (IGA 2), moderate (IGA 3), and severe (IGA 4). Dermoscopy was performed by handheld dermatoscope in polarized mode (Heine Delta 20T; $10 \times$ magnification) followed by videodermoscopy (Visiomed D200 ${ }^{\mathrm{EVO}}$; $15-200 \times$ magnification). Dermoscopic evaluation consisted of the analysis of the following features: presence and color of scales (white/yellow), distribution of scales (diffuse/patchy/central/peripheral), morphology of vessels (dotted/globular/linear), distribution of vessels (regular/clustered/ring pattern/unspecific), and presence of hemorrhagic spots, hemorrhagic crusts, white lines, white or yellow structureless areas. In addition, at each study visit before the laser procedure, patients were asked about presence of the following subjective symptoms within the target psoriatic plaques: itching, burning, stinging, and pain. They were also asked to rate the intensity of subjective symptoms using the Verbal Rating Scale (VRS): absent (0), mild (1), moderate (2), or severe (3). The treatment tolerability was assessed by both the patient and the investigator on day $7,14,21$, and 28 with the three-level scoring: good, moderate, and poor. Presence of subjective symptoms such as 
Table 1 Clinical characteristics of study participants

Study participants $(n=10)$

Age (years)

Mean \pm SD

$37.4 \pm 16.17$

Median 36

Range

12-69

Sex, $n(\%)$

Male

Female

Duration of psoriasis (years)

Mean \pm SD

$9.7 \pm 9.65$

Median

4.5

Range

$1-27$

Duration of target plaque (months)

Mean \pm SD

$39.25 \pm 72.83$

Median

11

Range

$1.5-240$

Location of target plaque, $n(\%)$

Upper limb

Lower limb

$6(60)$

Trunk

Family history of psoriasis, $n$ (\%)

$2(20)$

Intensity of pruritus (four-point scale), points

Mean \pm SD

$1.6 \pm 1.08$

Median

2

Range

0-3

IGA at baseline

Mean \pm SD

$2.3 \pm 0.48$

Median

2

Range

$2-3$

IGA at day 28

Mean \pm SD

$1.8 \pm 0.42$

Median

2

Range

1-2

mPASI at baseline, points 
Table 1 continued

\begin{tabular}{ll}
\hline & Study participants $(\boldsymbol{n}=\mathbf{1 0})$ \\
\hline Mean \pm SD & $6 \pm 1.7$ \\
Median & 5 \\
Range & $4-9$ \\
mPASI at day 28, points & \\
Mean \pm SD & $4.3 \pm 1.06$ \\
Median & 4.5 \\
Range & $3-6$ \\
\hline
\end{tabular}

$I G A$ Investigator Global Assessment, $m P A S I$ modified Psoriasis Area and Severity Index

pain or burning during and after the procedure, as well as oozing and crusting after laser session, were taken into consideration while assessing treatment tolerability. At the end of the study (follow-up visit on day 28), every patient was asked to subjectively assess the final outcome of the treatment with microsecond Nd:YAG laser using following descriptions: worsening, no improvement, slight improvement, marked improvement, and clearance of the skin lesions.

\section{Statistical Analysis}

Statistical analysis was performed using Statistica $^{\circledR} 13.0$ (TIBCO Software Inc.). Numerical data are expressed as mean with standard deviation (SD) of the mean and median. Categorical data are presented as numbers and percentages. Paired-samples Wilcoxon test was used for comparisons before and after laser treatment. $p$ Values less than 0.05 were considered significant.

\section{RESULTS}

\section{Disease Severity}

Significant improvement of each of the mPASI components (erythema, induration, and desquamation) was observed during the study (Fig. 1). The most significant improvement for erythema and induration was noticeable on day 14 , and for desquamation on day 21 . Regarding the total mPASI scoring, the mean mPASI score on day 0 (baseline) was $6.0 \pm 1.7$ and significantly decreased to $4.3 \pm 1.1$ after treatment with microsecond Nd:YAG laser $(p=0.01)$ (Fig. 2). Despite significant improvement, the maximal mean reduction of mPASI was only $30.3 \%$, which was noted on day 14 (Fig. 3).

At baseline, three patients were assessed as "moderate," and seven as "mild" according to IGA, while at follow-up visit on day 28, eight patients were scored as "mild," and two patients as "almost clear" (Fig. 4).

\section{Subjective Sensations}

Before laser treatment initiation, most patients $(8 / 10 ; 80 \%)$ suffered from pruritus within the target psoriatic plaques (mild 2/10; moderate 4/10; severe 2/10). At baseline (day 0), the mean intensity of pruritus on a four-point scale (VRS) was $1.6 \pm 1.1$ points. Microsecond Nd:YAG laser treatment led to a significant reduction of pruritus intensity within the target psoriatic plaques. On day 7, mean score of VRS was $0.6 \pm 0.7$, and on day 14 , mean score was $0.5 \pm 0.7$ points. On days 21 and 28 , none of 


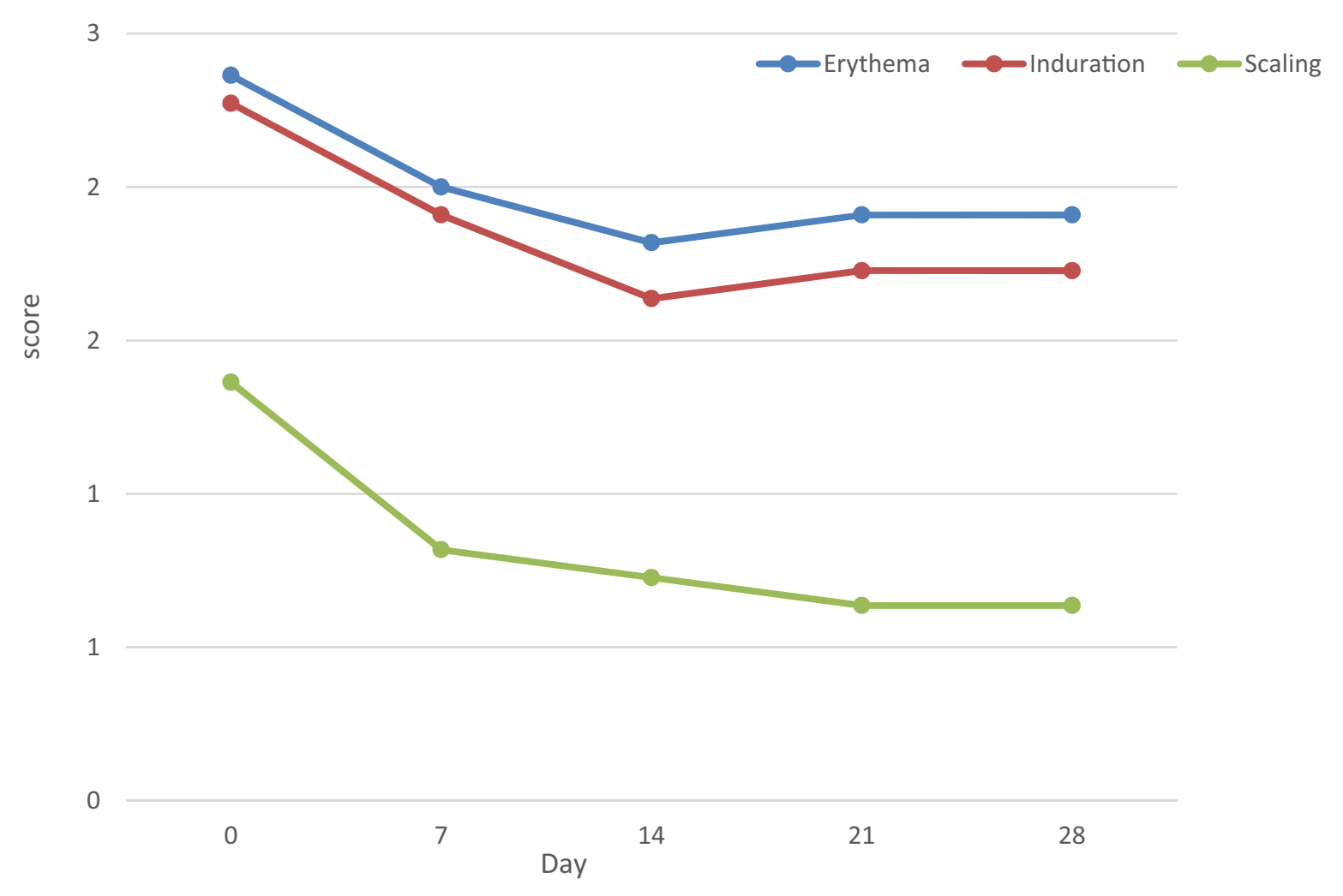

Fig. 1 Evolution of severity of erythema, induration, and scaling throughout microsecond Nd:YAG laser treatment

the study participants experienced itching within the target plaques (Fig. 5).

Regarding other sensations, one patient suffered from mild stinging, and one patient complained of moderate burning within the target plaques on baseline, but subsequently none of our patients reported these symptoms at next study visits.

\section{Tolerability and Final Treatment Outcome}

Three patients (30\%) complained of moderate treatment tolerance at each study visit because of the development of significant crusts within the treated area. In these cases, the investigator also assessed tolerance of the treatment as moderate. In addition, in one case, numerous punctate crusts developed within the lasertreated psoriatic plaque, which was rated as moderated tolerance of the procedure by the patient, but good in the view of the investigator.
According to the subjective assessment of treatment efficacy performed by study participants on day 28 , three patients reported no improvement, four patients reported slight improvement, and three patients reported marked improvement. No study participant complained of worsening of the treated lesions. However, total clearance of the target plaque was not reported, either.

\section{Dermoscopic Evaluation}

At baseline (day 0), before initiation of laser treatment, scales was observed under dermoscopy in 9/10 (90\%) patients, and it was white in the majority of cases $(7 / 10 ; 70 \%)$. Yellow scales were noted in $2 / 10$ (20\%) subjects. The distribution of scales was mainly diffuse (4/ $10 ; 40 \%$ cases $)$ or patchy $(3 / 10 ; 30 \%$ cases $)$, but central or peripheral scaling was also observed in some cases $(2 / 10 ; 20 \%$ and $2 / 10 ; 20 \%$, respectively). Dotted vessels were observed in $4 / 10$ (40\%) subjects, and globular vessels in 6/10 


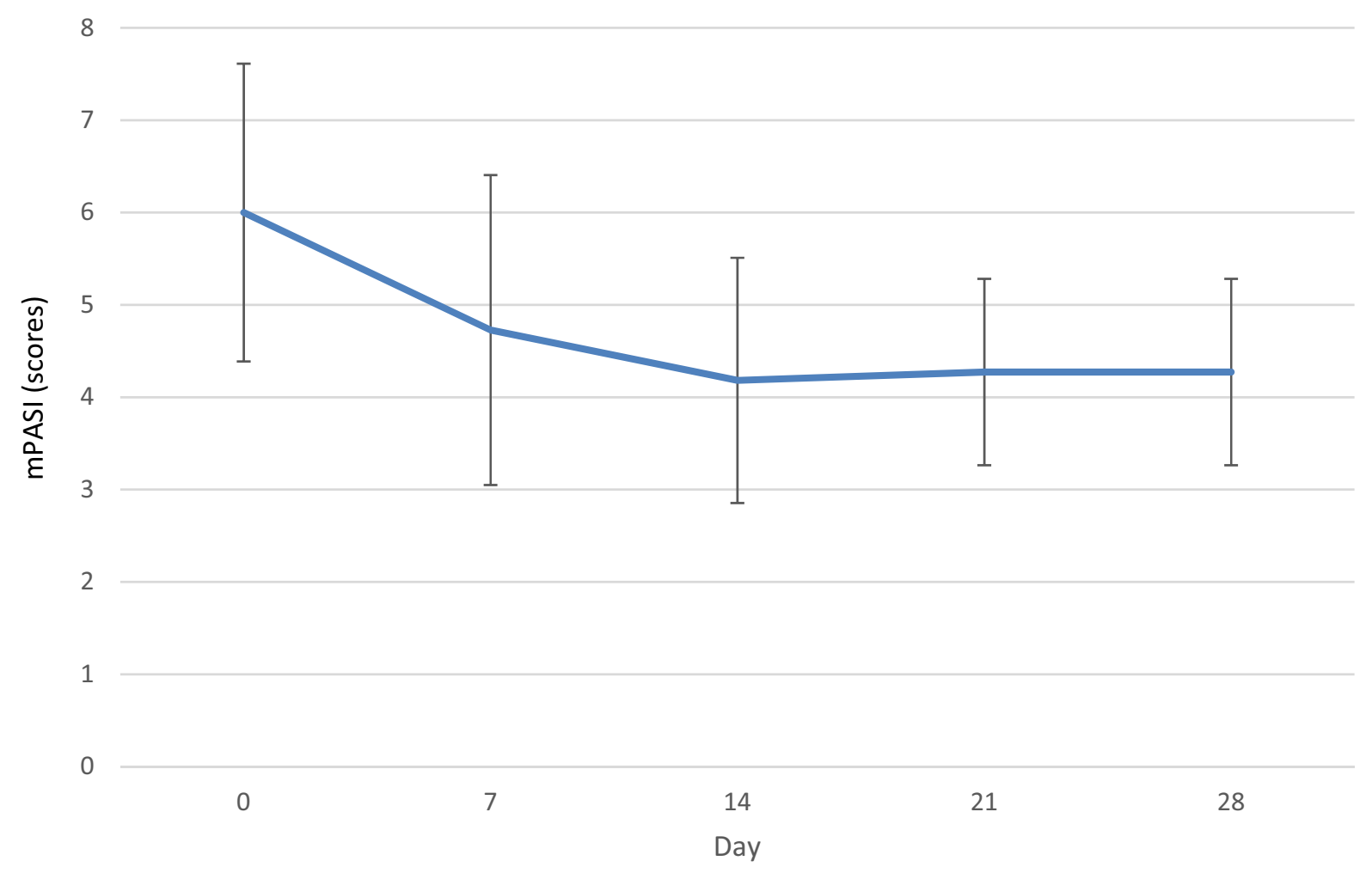

Fig. 2 Evolution of mean mPASI of target psoriatic plaques throughout microsecond Nd:YAG laser treatment

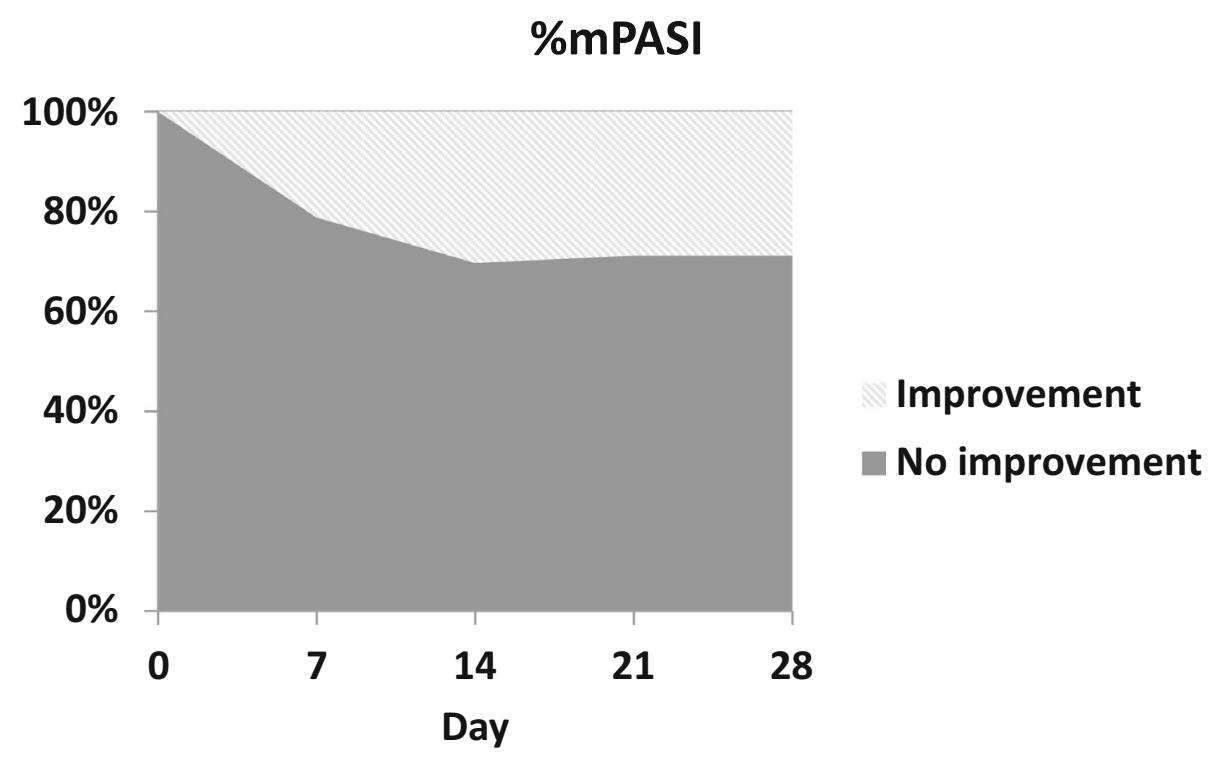

Fig. 3 Mean percentage reduction of mPASI in subjects treated with 650-microsecond Nd-YAG laser

$(60 \%)$ cases. Vessel distribution included regular $(3 / 10 ; 30 \%)$, clustered $(1 / 10 ; 10 \%)$, ring $(3 / 10$; $30 \%)$, and unspecific $(3 / 10 ; 30 \%)$ patterns. In addition, linear vessels, mainly at the periphery of the psoriatic plaques, were noted in $3 / 10$ $(30 \%)$ subjects. Other dermoscopic findings 


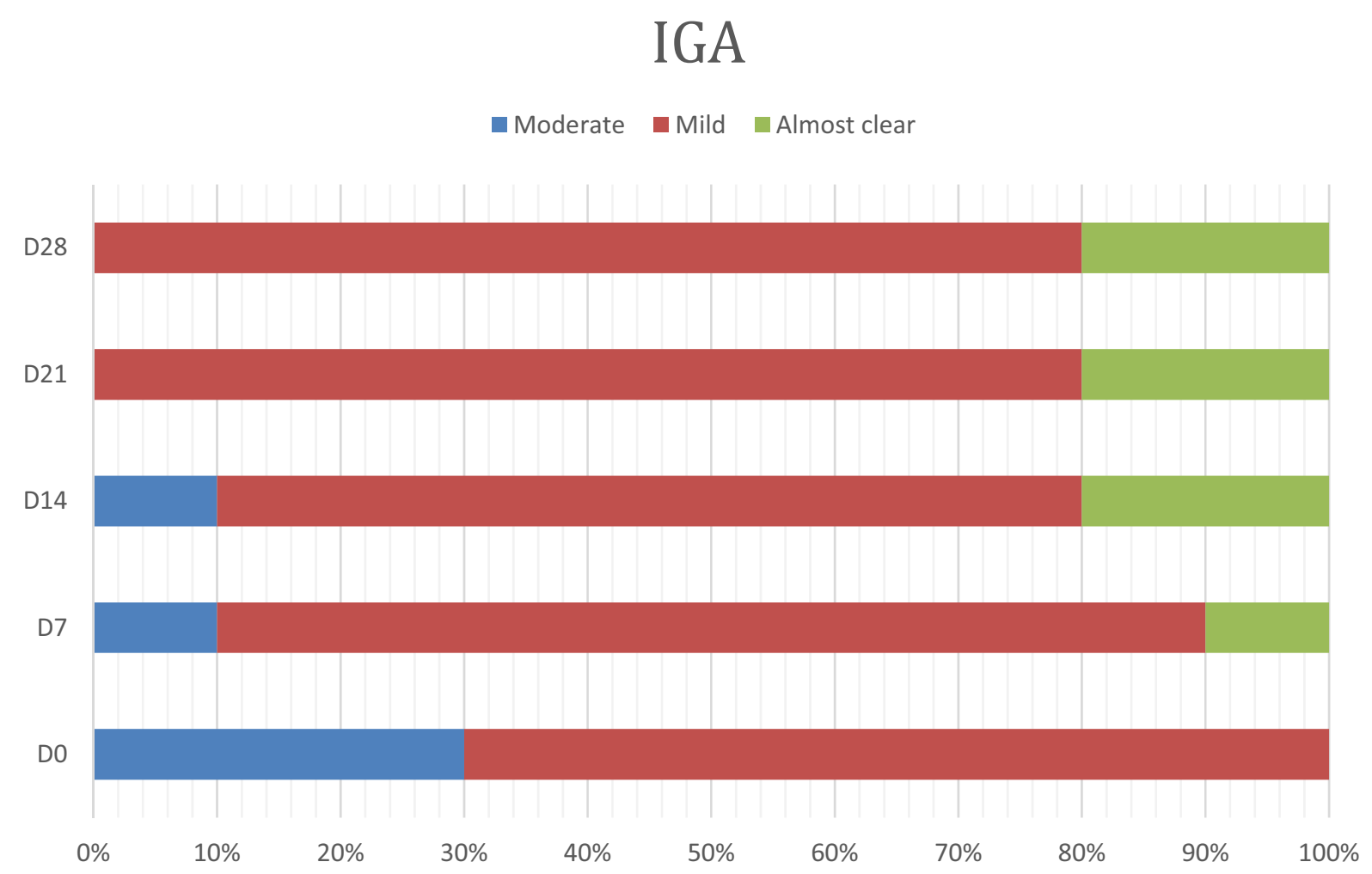

Fig. 4 Distribution of IGA categories in study participants at each visit

\section{The evolution of pruritus}

3

2

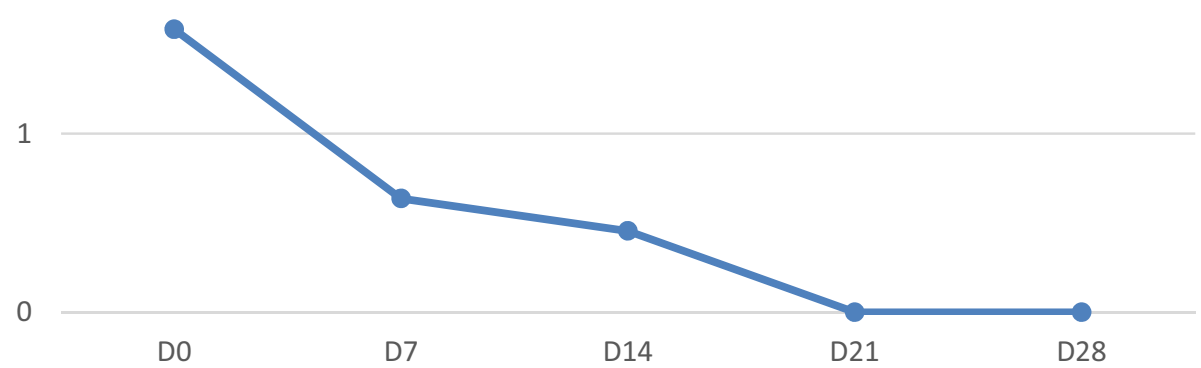

Fig. 5 Evolution of pruritus within target psoriatic plaques in subjects treated with 650-microsecond Nd:YAG laser

included hemorrhagic spots $(7 / 10 ; 70 \%)$, white lines $(3 / 10 ; 30 \%)$, white structureless areas $(1 /$ $10 ; 10 \%)$, and yellow structureless areas (4/10; $40 \%)$. On day 28 , after four sessions of laser treatment, white and yellow scaling was noted with the same frequencies and with small differences in the distribution. Dotted vessels were noted in 3/10 (30\%) subjects, globular vessels in 
Table 2 Dermoscopic features of psoriatic plaques before (baseline, day 0) and after four sessions of 650-microsecond Nd:YAG laser treatment (day 28)

\begin{tabular}{|c|c|c|c|c|c|c|}
\hline \multirow{2}{*}{$\begin{array}{l}\text { Dermoscopic } \\
\text { features }\end{array}$} & \multicolumn{3}{|c|}{ Baseline (D0) } & \multicolumn{3}{|l|}{ D28 } \\
\hline & $\begin{array}{l}\text { Total } \\
n=10\end{array}$ & $\begin{array}{l}\text { No } \\
\text { improvement } \\
\text { at day } 28 \\
n=3\end{array}$ & $\begin{array}{l}\text { Slight or marked } \\
\text { improvement at day } \\
28 \\
n=7\end{array}$ & $\begin{array}{l}\text { Total } \\
n=10\end{array}$ & $\begin{array}{l}\text { No } \\
\text { improvement } \\
\text { at day } 28 \\
n=3\end{array}$ & $\begin{array}{l}\text { Slight or marked } \\
\text { improvement at day } \\
28 \\
n=7\end{array}$ \\
\hline Scales, $n(\%)$ & $9(90)$ & $2(66.7)$ & $7(100)$ & $9(90)$ & $3(100)$ & $6(85.7)$ \\
\hline White scales & $7(70)$ & $1(33.3)$ & $6(85.7)$ & $7(70)$ & $2(66.7)$ & $5(71.4)$ \\
\hline Diffuse & $3(30)$ & - & $3(42.9)$ & $1(10)$ & - & $1(14.3)$ \\
\hline Patchy & $3(30)$ & $1(33.3)$ & $2(28.6)$ & $4(40)$ & $1(33.3)$ & $3(42.9)$ \\
\hline Central & $1(10)$ & - & $1(14.3)$ & - & - & - \\
\hline Peripheral & $1(10)$ & - & $1(14.3)$ & $3(30)$ & $1(33.3)$ & $2(28.6)$ \\
\hline Yellow scales & $2(20)$ & $1(33.3)$ & $1(14.3)$ & $2(20)$ & $1(33.3)$ & $1(14.3)$ \\
\hline Diffuse & $1(10)$ & - & $1(14.3)$ & - & - & - \\
\hline Patchy & - & - & - & $2(20)$ & $1(33.3)$ & $1(14.3)$ \\
\hline Central & $1(10)$ & $1(33.3)$ & - & - & - & - \\
\hline Peripheral & $1(10)$ & $1(33.3)$ & - & - & - & - \\
\hline Vessels, $n(\%)$ & $10(100)$ & $3(100)$ & $7(100)$ & $10(100)$ & $3(100)$ & $7(100)$ \\
\hline Dotted vessels & $4(40)$ & - & $4(57.1)$ & $3(30)$ & - & $3(42.9)$ \\
\hline Regular & $1(10)$ & - & $1(14.3)$ & $1(10)$ & - & $1(14.3)$ \\
\hline Clustered & - & - & - & - & - & - \\
\hline Ring pattern & $1(10)$ & - & $1(14.3)$ & $1(10)$ & - & $1(14.3)$ \\
\hline Unspecific & $2(20)$ & - & $2(28.6)$ & $1(10)$ & - & $1(14.3)$ \\
\hline $\begin{array}{l}\text { Globular } \\
\text { vessels }\end{array}$ & $6(60)$ & $3(100)$ & $3(42.9)$ & $7(70)$ & $3(100)$ & $4(57.1)$ \\
\hline Regular & $2(20)$ & $1(33.3)$ & $1(14.3)$ & $2(20)$ & - & $2(28.6)$ \\
\hline Clustered & $1(10)$ & $1(33.3)$ & - & $1(10)$ & $1(33.3)$ & - \\
\hline Ring pattern & $2(20)$ & - & $2(28.6)$ & - & - & - \\
\hline Unspecific & $1(10)$ & $1(33.3)$ & - & $4(40)$ & $2(66.7)$ & $2(28.6)$ \\
\hline Linear vessels & $3(30)$ & - & $3(42.9)$ & $1(10)$ & $1(33.3)$ & - \\
\hline $\begin{array}{l}\text { Hemorrhagic } \\
\text { spots, } n(\%)\end{array}$ & $7(70)$ & - & $7(100)$ & $8(80)$ & $1(33.3)$ & $7(100)$ \\
\hline $\begin{array}{l}\text { Hemorrhagic } \\
\text { crusts, } n(\%)\end{array}$ & - & - & - & $6(60)$ & $1(33.3)$ & $5(71.4)$ \\
\hline $\begin{array}{l}\text { White lines, } \\
n(\%)\end{array}$ & $3(30)$ & - & $3(42.9)$ & $5(50)$ & $1(33.3)$ & $4(57.1)$ \\
\hline
\end{tabular}


Table 2 continued

\begin{tabular}{|c|c|c|c|c|c|c|}
\hline \multirow{2}{*}{$\begin{array}{l}\text { Dermoscopic } \\
\text { features }\end{array}$} & \multicolumn{3}{|c|}{ Baseline (D0) } & \multicolumn{3}{|l|}{ D28 } \\
\hline & $\begin{array}{l}\text { Total } \\
n=10\end{array}$ & $\begin{array}{l}\text { No } \\
\text { improvement } \\
\text { at day } 28 \\
n=3\end{array}$ & $\begin{array}{l}\text { Slight or marked } \\
\text { improvement at day } \\
28 \\
n=7\end{array}$ & $\begin{array}{l}\text { Total } \\
n=10\end{array}$ & $\begin{array}{l}\text { No } \\
\text { improvement } \\
\text { at day } 28 \\
n=3\end{array}$ & $\begin{array}{l}\text { Slight or marked } \\
\text { improvement at day } \\
28 \\
n=7\end{array}$ \\
\hline $\begin{array}{l}\text { White } \\
\text { structureless } \\
\text { areas, } n(\%)\end{array}$ & $1(10)$ & - & $1(14.3)$ & $4(40)$ & $2(66.7)$ & $2(28.6)$ \\
\hline $\begin{array}{l}\text { Yellow } \\
\text { structureless } \\
\text { areas, } n(\%)\end{array}$ & $4(40)$ & $3(100)$ & $1(14.3)$ & $3(30)$ & $2(66.7)$ & $1(14.3)$ \\
\hline
\end{tabular}

$7 / 10(70 \%)$, and linear vessel in 1/10 (10\%) case. Increased frequency of white lines $(5 / 10 ; 50 \%)$ and white structureless areas $(4 / 10 ; 40 \%)$ was noted within laser treated plaques. In addition, hemorrhagic crusts were observed in 6/10 (60\%) subjects, which may be directly attributed to the laser procedure (details presented in Table 2).

Interestingly, all four subjects with predominant dotted vessels within the target plaque at baseline reported some benefit (slight or marked improvement) from the microsecond Nd-YAG laser treatment. On the other hand, three out of six subjects with globular vessels at baseline noticed some improvement on day 28 , while the other half did not report any benefit. All subjects with linear vessels, hemorrhagic spots, white lines, and white structureless areas, and the majority of patients (six out of seven) with white scales under dermoscopy at baseline, experienced benefit after laser treatment (Table 2).

\section{DISCUSSION}

Pathological vessels are an important component of the psoriatic plaque. The concept that vascular defect plays an important role in the pathogenesis of psoriasis has long been considered. The transformation of the skin microcirculation is indispensable to maintain clinical status of psoriatic plaques by delivering nutrition to cells and tissues, and stimulating migration of inflammatory cells [13]. In psoriasis, capillaries present in the dermal papillae are enlarged, dilated, and tortuous. Conventional topical treatments for psoriasis target the epidermal hyperplasia, but modern treatment procedures are becoming focused on angiogenic pathway modulation [14]. The initial studies showed a modification of the psoriatic microcirculation in conjunction with UVB therapy [15].

Currently, the excimer laser is the leader in the treatment of psoriatic plaques among various lasers [8]. The 1064-nm Nd:YAG laser is primarily used in the treatment of vascular lesions. Its mode of action is related to deep penetration, targeting dermal vasculature, and selective photothermolysis of hemoglobin. Recently, there has been growing interest in the use of Nd:YAG laser in a broader range of indications, including inflammatory dermatoses with increased vascularization, e.g., psoriasis (videodermoscopic photos of vessel changes within psoriatic lesions before and shortly after Nd-YAG laser application are presented in Fig. 6). The long-pulsed 1064-nm Nd:YAG laser has already been successfully used in the treatment of nail psoriasis [10-12]. On the other hand, data on the efficacy of Nd:YAG laser in 


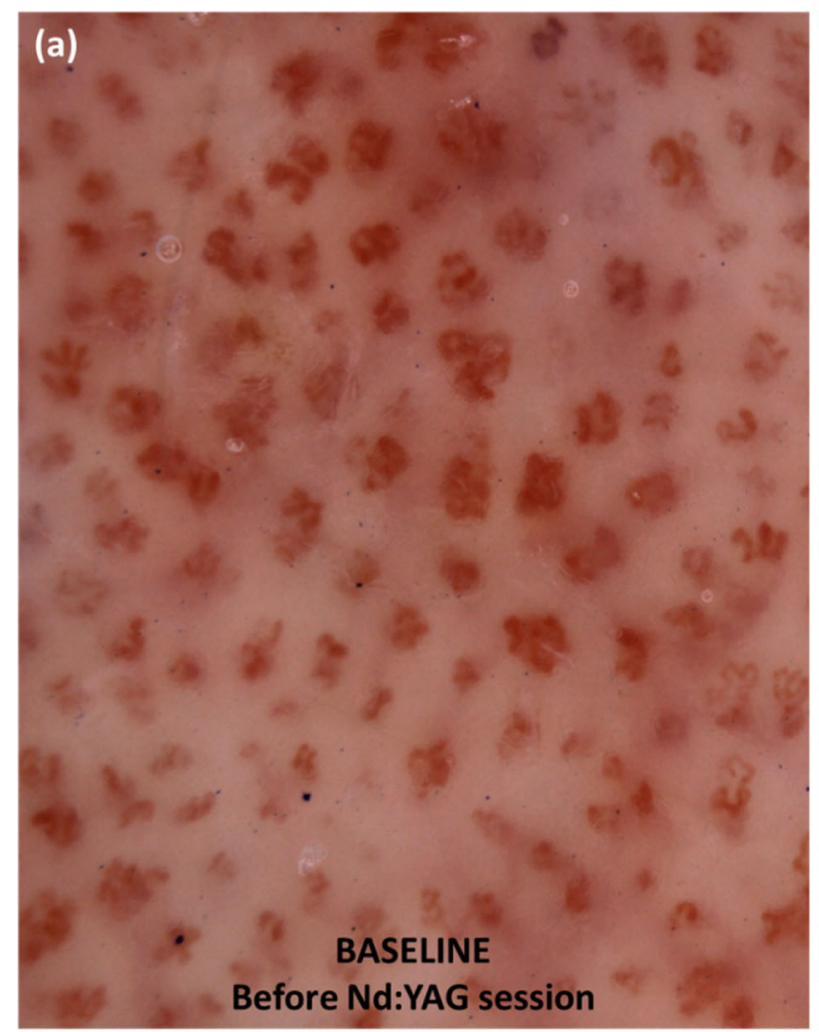

Fig. 6 a Videodermoscopy of target plaque before Nd:YAG laser procedure shows regularly distributed glomerular (bushy, basket-weave) vessels. b Videodermoscopy of the target plaque shortly after microsecond

the treatment of plaque psoriasis are scarce and conflicting (Table 3) [16, 17]. In the initial study by Ruiz-Esparza [16], low-energy irradiance with 1320-nm Nd:YAG laser led to clinical improvement in three patients with psoriasis vulgaris. On the other hand, van Lingen et al. [17] did not observe any additional value of long-pulsed 1064-nm Nd:YAG laser in the treatment of plaque psoriasis, when compared with standard therapy with calcipotriol/betamethasone dipropionate ointment. The authors reported a significant reduction in the cumulative score of erythema, induration, and scaling in subjects treated with long-pulsed Nd:YAG at week 4 compared with baseline, but this effect was not maintained further throughout the study [17].

The 650-microsecond 1064-nm Nd:YAG laser is a novel type of Nd-YAG laser with a pulse duration shorter than or equal to the time of thermal relaxation of the skin and blood vessels.

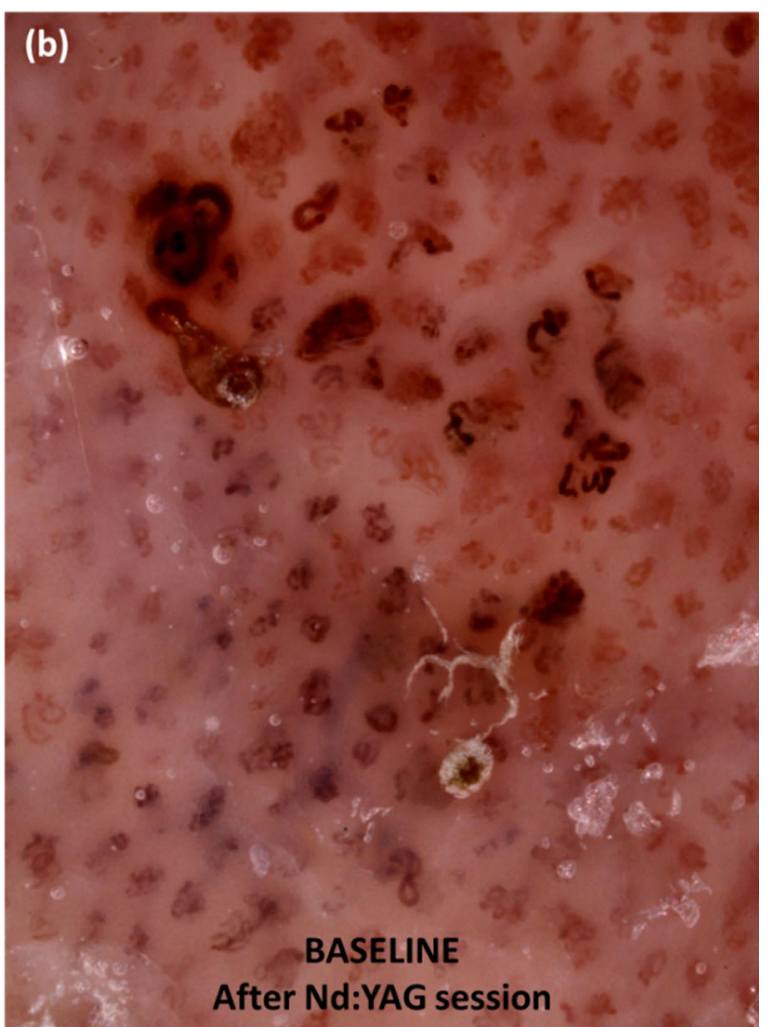

Nd:YAG laser procedure shows darkening of the bushy capillaries due to selective photothermolysis of hemoglobin

It does not require cooling, and due to the lesser thermal damage, its use is associated with lower rates of postinflammatory hyperpigmentation and scarring. It was initially used to remove unwanted hair, and subsequently its indications were extended to other conditions, including rosacea, onychomycosis, acne, and psoriasis [18]. The utility of 650-microsecond Nd:YAG laser in the treatment of psoriasis vulgaris was evaluated in a single study by Nestor et al. [18]. The authors compared the efficacy and tolerance of microsecond $\mathrm{Nd}$ :YAG laser versus 308-nm excimer laser in a randomized, investigator-blinded study conducted in 15 subjects with mild-to-moderate plaque psoriasis. The procedures were performed twice a week, or less often in case of full clearance of the treated areas. Multiple passes per treatment session were performed. At the end of the study, the median overall modified Psoriasis Area and 


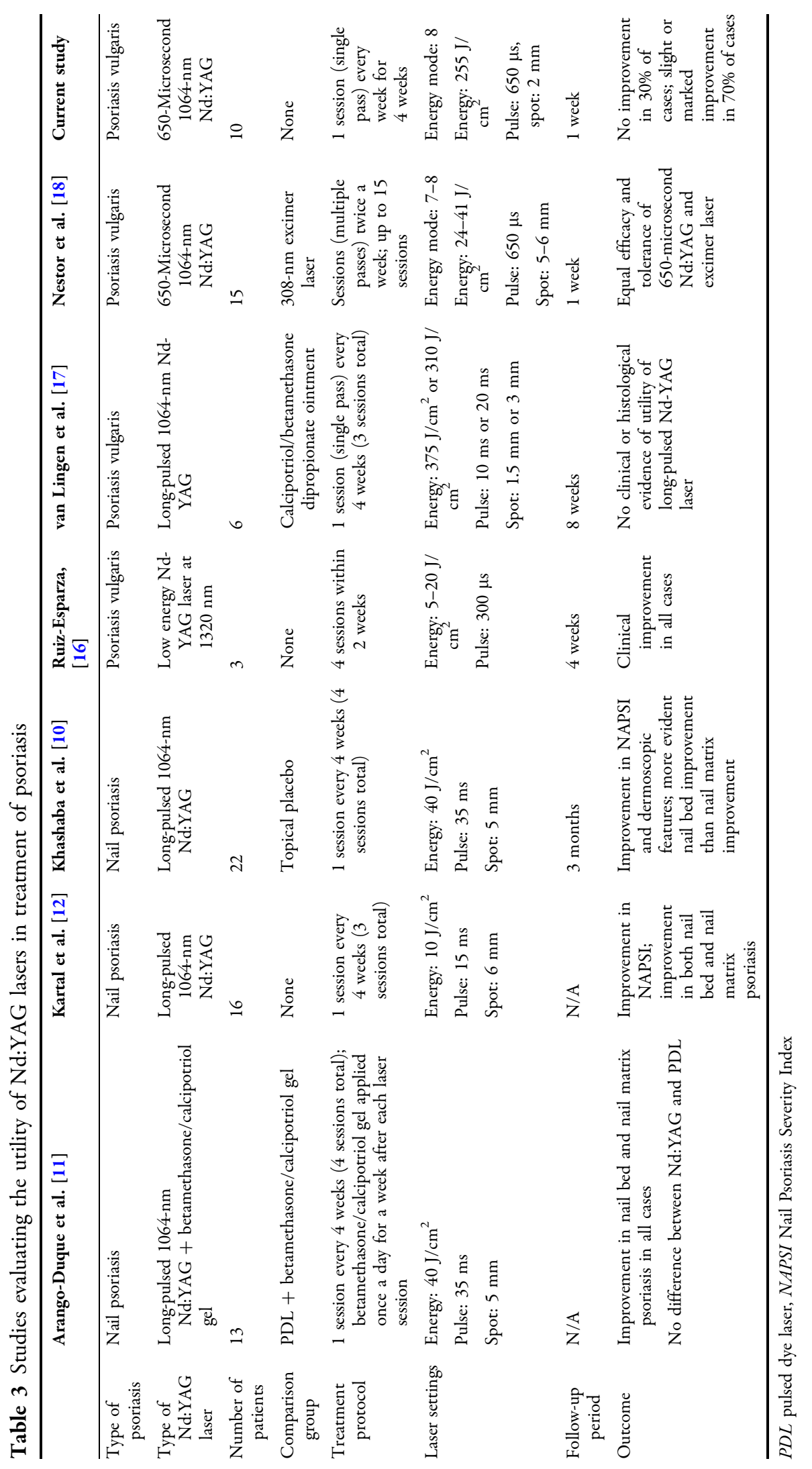


Severity Index (mPASI) for areas treated with microsecond Nd-YAG laser was 1.2, whereas the baseline value was 2.8 . The median itch intensity, measured with the numeric rating scale (NRS), was meaningfully lower at the end of the study than the baseline value $(p=0.0156)$. It is worth emphasizing that the results of the aforementioned study showed equal efficacy and tolerance of the 650-microsecond 1064-nm $\mathrm{Nd}$ :YAG laser and the 308-nm excimer laser in the treatment of mild-to-moderate psoriasis vulgaris [18].

In our study, some improvement of the target plaques, measured using mPASI and IGA, was noted after microsecond Nd-YAG laser treatment (clinical and dermoscopic examples are presented in Fig. 7). The baseline mean mPASI score was $6 \pm 1.7$, whereas at the end of the study this value was $4.3 \pm 1.06$. All study participants suffered from mild-to-moderate psoriasis (IGA 2-3) at inclusion, while the disease severity was evaluated as "almost clear" or "mild" (IGA 1-2) on day 28. It is also worth noting that the pruritus within psoriatic plaques subsided completely with laser treatment. Nevertheless, the maximal mean reduction of mPASI was only $30.3 \%$. In addition, only $30 \%$ of participants assessed subjectively the improvement as "marked" and $40 \%$ of subjects as "slight." In the view of three out of ten patients, the target plaques did not improve at all. The procedures were also associated with some oozing and crusting in several participants (tolerance rated as moderate). Therefore, we do not find the results of the current study satisfactory enough to consider the microsecond $\mathrm{Nd}$ :YAG laser treatment a good alternative to more accessible and less expensive topical therapies of proven efficacy.

Evaluation of the dermoscopic features to predict treatment response is a novel direction for application of noninvasive skin imaging techniques in general dermatology. Considering the small number of subjects in the current study, reliable statistical analysis cannot be performed. Nevertheless, we observed an interesting trend, which is largely in line with the results of previous research [19]. All patients $(n=4)$, who at baseline presented with predominant dotted vessels within target plaques under dermoscopy, experienced some benefit (slight or marked improvement) from microsecond Nd:YAG laser treatment. Similarly, improvement of the psoriatic plaques was noted in all subjects with hemorrhagic spots $(n=7)$ or linear vessels $(n=3)$ under dermoscopy. On the other hand, three out of six (50\%) participants with globular vessels at baseline did not report any improvement of the target plaques after laser treatment. In a recent study by Errichetti et al. [19], globular vessels were found to be a negative predictor of response to topical treatment with calcipotriol/betamethasone dipropionate foam. Globular vessels are characterized by a larger size than typically present in psoriasis (handheld dermoscopy, magnification $10 \times$ ) dotted vessels, and are more commonly observed on the lower limbs. In the current study, in five out of six subjects with globular vessels at baseline, the target plaques were located on the legs, which is consistent with previous findings. Presence of globular vessels under dermoscopy may result from more significant vascular dilatation and be a marker of increased blood flow with higher hydrostatic pressure [19]. So far, globular vessels have been found to be a dermoscopic marker of poor response to topical calcipotriol/betamethasone dipropionate treatment, and might also, on the basis of our observations, be related to resistance to microsecond Nd:YAG laser therapy.

Major limitations of the current study include the small number of participants and the short follow-up period. Larger studies, including combination therapy with topical and/or systemic antipsoriatics, are needed to reliably assess the utility of microsecond Nd:YAG laser in the treatment of plaque psoriasis.

\section{CONCLUSIONS}

The limited availability of 650-microsecond Nd:YAG lasers, the potential cost of a single procedure, and above all, the ambiguous results on its effectiveness in the treatment of plaque psoriasis do not encourage its choice as a firstor second-line therapy for this indication. Dermoscopic assessment may be of help in 


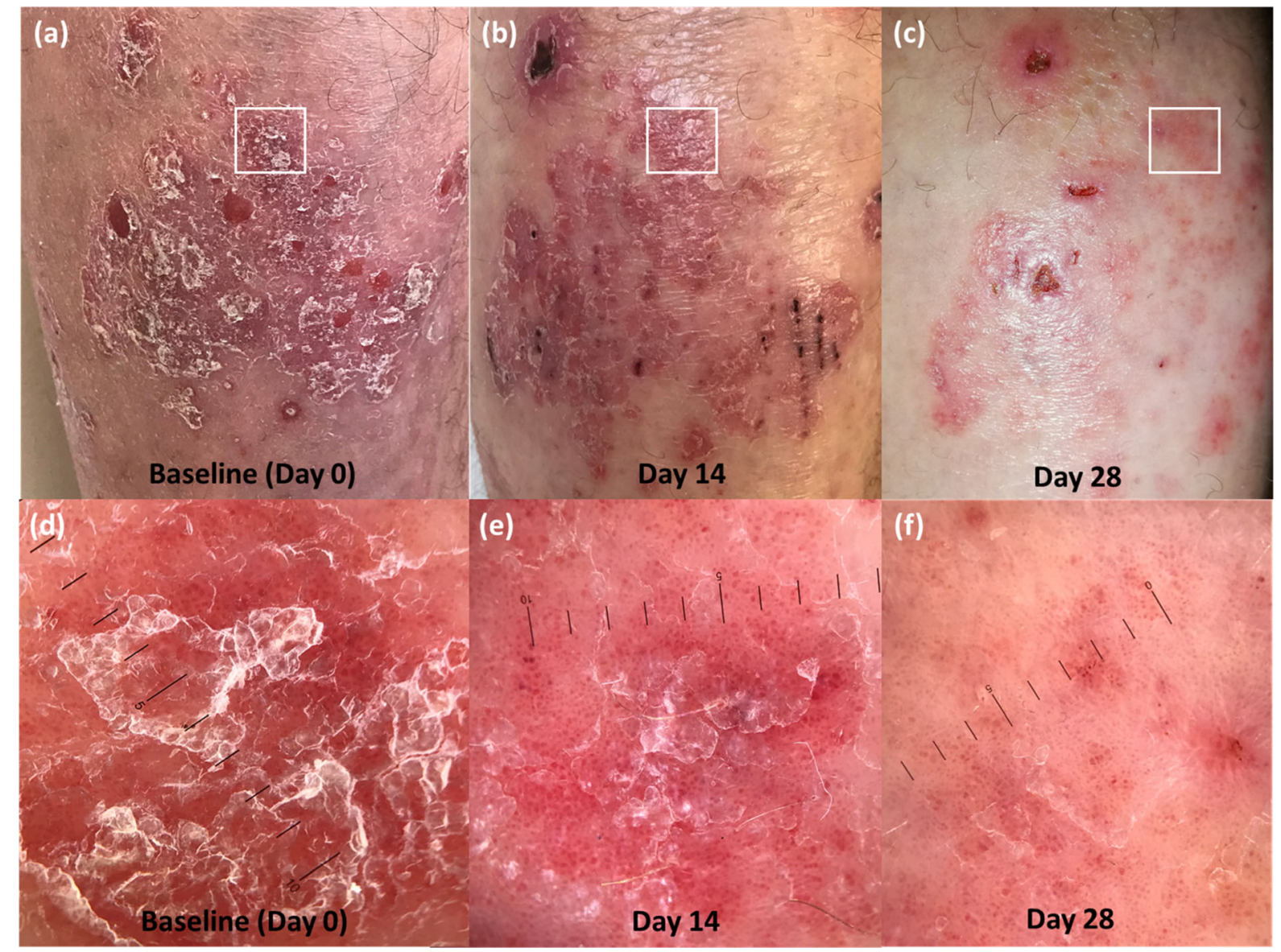

Fig. 7 Clinical photos of target plaque at baseline (a), on day 14 (b), and on day 28 (c). At the follow-up visit, the response to the microsecond $\mathrm{Nd}$ :YAG laser was rated by the patient as "marked." Corresponding dermoscopic images of the region marked with white square. d Patchy white scaling covering uniform globular vessels was observed at baseline. e Reduction of the severity of scaling,

identifying patients (or psoriatic plaques) that may benefit from the procedure. Microsecond Nd:YAG laser therapy, if used at all, should be primarily performed in patients with dotted vessels and/or hemorrhagic spots under dermoscopy. Nevertheless, a larger group of patients and longer follow-up period are required for reliable evaluation. which enabled better visualization of the regularly distributed globular vessels, was present on day 14 . f Significant reduction of scaling and decreased density of globular vessels, displaying irregular distribution, was noted at the follow-up visit on day 28

\section{ACKNOWLEDGEMENTS}

We would like to thank the study participants for their involvement.

Funding. The 650-microsecond Nd:YAG laser was provided courtesy of Into Beauty (Wroclaw, Poland). No funding or sponsorship was received for publication of this article. 
Authorship. All named authors meet the International Committee of Medical Journal Editors (ICMJE) criteria for authorship for this article, take responsibility for the integrity of the work as a whole, and have given their approval for this version to be published.

Disclosures. Marta Kołt-Kamińska and Magdalena Żychowska have nothing to disclose. Adam Reich has worked as a consultant or speaker for AbbVie, Bioderma, Celgene, Chema Elektromet, Eli Lilly, Galderma, Janssen, Leo Pharma, Medac, Menlo Therapeutics, Novartis, Pierre-Fabre, Sandoz, and Trevi, and participated as principal investigator or subinvestigator in clinical trials sponsored by AbbVie, Drug Delivery Solutions Ltd, Galderma, Genentech, Janssen, Kymab Limited, Leo Pharma, Menlo Therapeutics, MetrioPharm, MSD, Novartis, Pfizer, and Trevi. Adam Reich is a member of the journal's Editorial Board.

Compliance with Ethics Guidelines. The research was conducted in accordance with the Declaration of Helsinki and was approved by University of Rzeszow Ethics Committee. Informed consent was obtained from the patients for participation in the study and publication of the article, including publication of clinical photographs.

Data Availability. The datasets generated and/or analyzed during the current study are available from the corresponding author on reasonable request.

Open Access. This article is licensed under a Creative Commons Attribution-NonCommercial 4.0 International License, which permits any non-commercial use, sharing, adaptation, distribution and reproduction in any medium or format, as long as you give appropriate credit to the original author(s) and the source, provide a link to the Creative Commons licence, and indicate if changes were made. The images or other third party material in this article are included in the article's Creative Commons licence, unless indicated otherwise in a credit line to the material. If material is not included in the article's Creative Commons licence and your intended use is not permitted by statutory regulation or exceeds the permitted use, you will need to obtain permission directly from the copyright holder. To view a copy of this licence, visit http://creativecommons.org/licenses/by$\mathrm{nc} / 4.0 /$.

\section{REFERENCES}

1. Samotij D, Nedoszytko B, Bartosińska J et al. Pathogenesis of psoriasis in the "omic" era. Part I. Epidemiology, clinical manifestation, immunological and neuroendocrine disturbances. Postepy Dermatol Alergol. 2020;37(2):135-53.

2. Nedoszytko B, Szczerkowska-Dobosz A, StawczykMacieja $\mathrm{M}$ et al. Pathogenesis of psoriasis in the "omic" era. Part II. Genetic, genomic and epigenetic changes in psoriasis. Postepy Dermatol Alergol. 2020;37(3):283-98.

3. Michalek IM, Loring B, John SM. A systematic review of worldwide epidemiology of psoriasis. J Eur Acad Dermatol Venereol. 2017;31:205-12.

4. Kołt-Kamińska M, Koziak $\mathrm{K}$, Dutkiewicz $\mathrm{M}$, Zegrocka-Stendel O, Reich A. Can topical cefazolin be an useful treatment for psoriasis? Forum Dermatol. 2020;6:43-9.

5. Narbutt J, Wolska H, Kaszuba A et al. Photoprotection. Recommendations of the Polish Dermatological Society. Part 1: ultraviolet radiation and sunscreens. Dermatol Rev. 2018;105:30-40.

6. Weinstabl A, Hoff-Lesch S, Merk HF, von Felbert V. Prospective randomized study on the efficacy of blue light in the treatment of psoriasis vulgaris. Dermatology. 2011;223(3):251-9.

7. Bónis B, Kemény L, Dobozy A, Bor Z, Szabó G, Ignácz F. 308 nm UVB excimer laser for psoriasis. Lancet. 1997;350(9090):1522.

8. He YL, Zhang XY, Dong J, Xu JZ, Wang J. Clinical efficacy of a $308 \mathrm{~nm}$ excimer laser for treatment of psoriasis vulgaris. Photodermatol Photoimmunol Photomed. 2007;23(6):238-41.

9. Fritz K, Salavastru C. 308 nm-Excimerlaser zur Therapie von Psoriasis und entzündlichen Hauterkrankungen. Hautarzt. 2018;69(1):35-43.

10. Khashaba SA, Gamil H, Salah R, Salah E. Efficacy of long-pulsed Nd-YAG laser in the treatment of nail psoriasis: a clinical and dermoscopic evaluation. J Dermatolog Treat. 2019;24:1-7. 
11. Arango-Duque LC, Roncero-Riesco M, Usero Bárcena T, Palacios Álvarez I, Fernández López E. Treatment of nail psoriasis with Pulse Dye Laser plus calcipotriol betamethasone gel vs. Nd:YAG plus calcipotriol betamethasone gel: an intrapatient left-to-right controlled study. Actas Dermosifiliogr. 2017; 108:140-4.

12. Kartal SP, Canpolat F, Gonul M, Ergin C, Gencturk Z. Long-pulsed Nd:YAG laser treatment for nail psoriasis. Dermatol Surg. 2018;44:227-33.

13. Hern S, Stanton AW, Mellor RH, et al. In vivo quantification of the structural abnormalities in psoriatic microvessels before and after pulsed dye laser treatment. Br J Dermatol. 2005;152:505-11.

14. Pandya NM, Dhalla NS, Santani DD. Angiogenesis-a new target for future therapy. Vascul Pharmacol. 2006;44:265-74.

15. Horacek J. Ultrastructural changes of capillaries by UV in psoriatic lesions (author's transl). Z Hautkr. 1981;56:1218-23.
16. Ruiz-Esparza J. Clinical response of psoriasis to lowenergy irradiance with the Nd-YAG laser at 1320nm report of an observation in three cases. Dermatol Surg. 1999;25:403-7.

17. van Lingen RG, de Jong EM, van Erp PE, van Meeteren WS, van De Kerkhof PC, Seyger MM. Nd: YAG laser (1064 nm) fails to improve localized plaque type psoriasis: a clinical and immunohistochemical pilot study. Eur J Dermatol. 2008;18: 671-6.

18. Nestor MS, Fischer D, Arnold D. Randomized, investigator-blinded study to compare the efficacy and tolerance of a 650-microsecond, 1064-nm YAG laser to a 308-nm excimer laser for the treatment of mild to moderate psoriasis vulgaris. J Drugs Dermatol. 2020;19(2):176-83.

19. Errichetti E, Croatto M, Arnoldo L, Stinco G. Plaque-type psoriasis treated with calcipotriene plus betamethasone dipropionate aerosol foam: a prospective study on clinical and dermoscopic predictor factors in response achievement and retention. Dermatol Ther (Heidelb). 2020;10: 757-67. 